Volumen 24, No 1, Páginas 31-36

IDESIA (Chile) Enero - Abril 2006

\title{
INDUCCIÓN FLORAL DE ARRACACHA (ARRACACIA XANTHORRHIZA BANCROFT)
}

\author{
FLORAL INDUCTION OF ARRACACHA \\ (ARRACACIA XANTHORRHIZA BANCROFT)
}

\author{
Raúl Blas-Sevillano, R. ${ }^{1}$; Alberto Julca-Otiniano ${ }^{1}$; Jean P. Baudon ${ }^{2}$
}

\begin{abstract}
RESUMEN
Una prueba de inducción floral fue efectuada, utilizando los "colinos" de las 3 principales formas hortícolas de Arracacia xanthorrhiza blanca, amarilla y púrpura provenientes del Perú. El objetivo fue encontrar factores involucrados en los procesos de inducción floral. Se deshidrataron los colinos a tres niveles de pérdida de peso, y se aplicaron tres niveles de estrés hídrico en el substrato (cantidad de agua disponible). Estos fueron conducidos en diferentes condiciones climáticas, utilizando cámaras controladas (fueron simuladas las condiciones climáticas de los Andes centrales) y un invernadero. Los resultados concernientes al estrés hídrico y la deshidratación de los "colinos" no permitieron poner en evidencia una tendencia clara sobre la inducción floral de la arracacha. La floración fue variable según los genotipos.
\end{abstract}

Palabras clave: Inducción floral, Arracacia xanthorrhiza.

\begin{abstract}
The induction floral test was carried out using "colinos" of the three main horticultural forms: white, yellow and purple of Perú. The objective was to identify factors involved in the processes of floral induction. The "colinos" were dehydrated at three levels of weight loss and three levels of stress hydric in the substratum (amount of available water). These trials were conducted in different climatic conditions, using controlled chambers (where the climatic conditions of the central Andes were simulated) and a greenhouse. The results concerning stress hydric and the dehydration of "colinos" did not allow us to create a clear pathway on the floral induction of arracacha. Flowering was variable according to the genotypes.
\end{abstract}

Key words: Floral induction, Arracacia xanthorrhiza.

\section{INTRODUCCIÓN}

La arracacha es una planta andina herbácea y perenne, de la familia Apiaceae (Hodge, 1954; Mathias \& Constance, 1962; León, 1964; Cárdenas, 1969, y Brako \& Zarucchi, 1993). En Perú se la encuentra cultivada entre 600 y 3.600 msnm, y actualmente se estima una superficie cultivada de 1.200 ha (MA, 2004).

La planta es herbácea, tiene cuatro partes distintivas (raíz reservante, tallo llamado "cepa", los hijuelos o ramas laterales llamados "colinos" y las hojas e inflorescencias). Se propaga vegetativamente a través de "colinos", una planta puede producir en promedio entre 15 y 40 "colinos" por campaña. El eje floral presenta alrededor de 15-20 umbelas compuestas. La inflorescencia es una umbela compuesta con 8-14 umbelulas. Cada umbelula lleva 10-25 flores (Blas, 2005). La flor es perfecta en la parte externa de la umbelula (flores con gineceo y androceo funcional), sin embargo en la parte interna solo existen normalmente flores estaminadas (Hermann, 1997). Las flores son muy pequeñas y el fruto desarrolla solamente un máximo de dos granos.

1 Universidad Nacional Agraria, La Molina, Ap. 456, Lima, Perú, e-mail: rblas@lamolina.edu.pe

2 Faculté Universitaire des Sciences Agronomiques de Gembloux, Passage des Déportés, 2, B. 5030 Gembloux, Belgique.

Fecha de Recepción: 28 Febrero de 2006

Fecha de Aceptación: 12 Abril de 2006 
En los Andes rara vez se observa la floración, pero es frecuente en zonas que se encuentran sobre los $900 \mathrm{~m}$ de altitud y $20^{\circ}$ latitud sur, como es el caso de los estados meridionales de Brasil (Minas Gerais, Sâo Paulo y Paraná). Se considera que los factores que influyen en la floración de la arracacha no están claramente definidos. Para algunos investigadores en Brasil (Zanin y Casali, 1984), la floración que ocurre entre julio y octubre se debe a las bajas temperaturas y los días cortos que se presentan a mediados del año. Pero otros autores han señalado que la deshidratación de las partes aéreas de las plantas adultas y su cultivo posterior induce la floración en $90 \%$ de las plantas, tal como se ha corroborado en Brasil y Ecuador (Hermann, 1997).

En consecuencia, la floración de la arracacha es muy irregular y no ha sido estudiada adecuadamente hasta la fecha. Por ello, identificar los factores que afectan la formación de la flor es importante para trabajos futuros de biosistemática, mejoramiento genético y para la gestión de los bancos de germoplasma de la especie en la región Andina, por lo que es necesario poner atención particular a la inducción floral, a los sistemas de reproducción, a la semilla y a su germinación. Considerando estos antecedentes, el objetivo del presente trabajo fue identificar los factores involucrados en los procesos de inducción floral de la arracacha.

\section{MATERIALES Y MÉTODOS}

Se usaron "colinos" de las tres principales formas hortícolas de arracacha peruana (blanca, amarilla y púrpura), según se observa en la Tabla 1.
El estudio se llevó a cabo en dos experimentos:

Primer ensayo: se ha probado la respuesta a la inducción floral de la deshidratación de los colinos y el estrés hídrico al sustrato del cultivo.

\section{Deshidratación de los colinos}

Se utilizaron los "colinos" de las entradas RBS15, RBS-16 y RBS-17 (las entradas AYAC-1, AYAC-2, no estuvieron disponibles en esta etapa). Los "colinos" fueron deshidratados a temperatura ambiente $\left(20^{\circ} \mathrm{C}\right)$ hasta la pérdida del $60 \%$ de su peso a la cosecha (fueron deshidratados durante 45 días). Posteriormente, el material deshidratado fue dividido en dos partes y sembrado en diferentes condiciones (mínimo 20 colinos por entrada, Tabla 2, RBS-17 no fue incluido en el invernadero por material insuficiente). La primera mitad en una cámara con una temperatura de $20^{\circ} \mathrm{C}$ y un fotoperíodo de $12 \mathrm{~h}$; la otra mitad en un invernadero con una temperatura de $22{ }^{\circ} \mathrm{C}$ y un fotoperíodo de 9-11 h. En ambas condiciones permanecieron durante 28 días. Se realizaron dos observaciones de la inducción (a los 20 y 28 días después de la plantación), considerando que la inducción floral corresponde a la presencia de 1 ó 2 nudos en eje (ta1lo) floral (Figura 1). Después de la segunda observación, las plantas con inducción floral de la cámara acondicionada fueron transferidas al invernadero, para completar el desarrollo de la inflorescencia de las plantas.

\section{Estrés hídrico en el sustrato}

Se utilizaron las plantas de la forma hortícola blanca (RBS-15, en las dos entradas restantes no

Tabla 1

Procedencia del material vegetal utilizado para los ensayos de inducción floral

\begin{tabular}{|l|l|l|l|}
\hline Entrada & Departamento & Provincia & Forma hortícola \\
\hline RBS-15 & Amazonas & Pedro Ruiz & blanca \\
RBS-16 & Amazonas & Pedro Ruiz & amarillo \\
RBS-17 & Amazonas & Pedro Ruiz & púrpura \\
AYAC-1 & Apurímac & Andahuaylas & blanca \\
AYAC-2 & Apurímac & Andahuaylas & amarillo \\
\hline
\end{tabular}




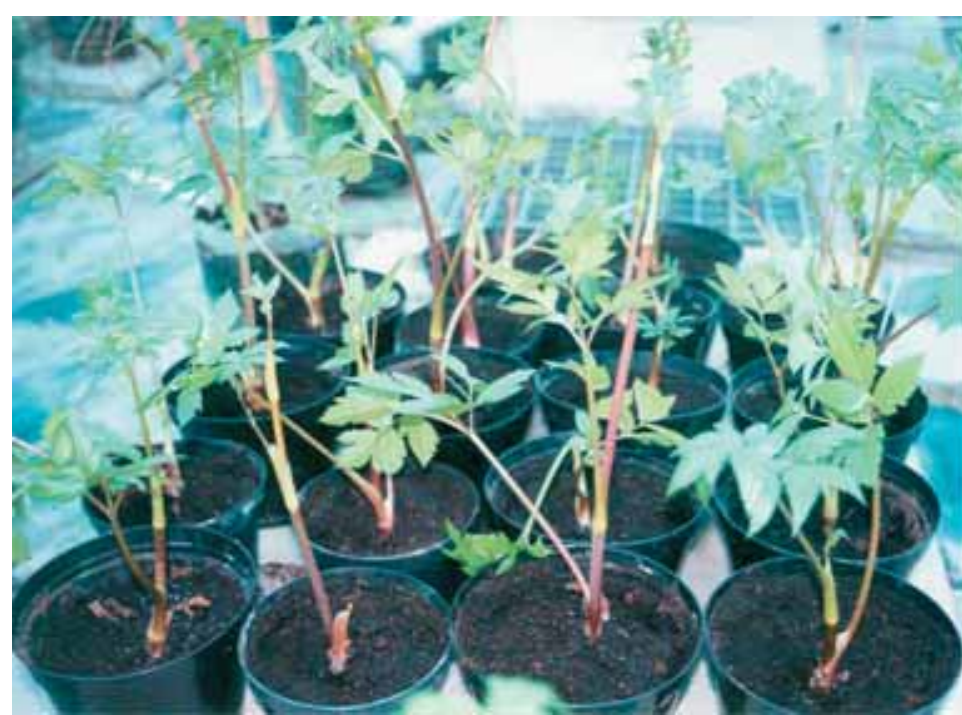

A. Inducción floral.

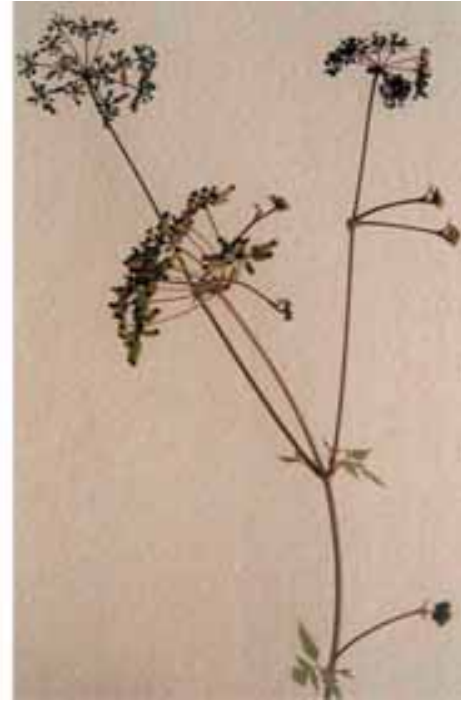

B. Eje floral de la arracacha.

Figura 1. Floración y estructuras generativas de la arracacha.

se tuvo material suficiente) que no presentaron inducción floral en el transcurso del ensayo precedente (deshidratación de colinos y diferentes condiciones climáticas), durante tres meses después de su plantación. Estas plantas fueron transplantadas en macetas de 7,6 litros, conteniendo un substrato constituido de arena, turba, tierra en proporciones de 1:2:2, respectivamente. Luego fueron llevadas a una cámara acondicionada con una temperatura diurna de $22^{\circ} \mathrm{C}$ y nocturna de $10^{\circ} \mathrm{C}$, bajo un fotoperíodo de $12 \mathrm{~h}$ y humedad relativa de $65 \%$. Luego de un buen establecimiento de las plantas a la nueva condición climática, éstas fueron sometidas a los tres siguientes niveles de estrés hídrico y el testigo:

sh1 : estrés hídrico nivel 1 (45-60\% cantidad de agua disponible).

sh2 : estrés hídrico nivel 2 (30-45\% cantidad de agua disponible).

sh3 : estrés hídrico nivel 3 (15-30\% cantidad de agua disponible).

$\mathrm{T}$ : Testigo (a capacidad de campo, $100 \%$ cantidad de agua disponible).

Al principio, el conjunto de los substratos se caracteriza por un tenor de agua que corresponde a capacidad de campo. Enseguida se dejó de regar las macetas durante 1 día para el tratamiento sh1,
2 días para el tratamiento sh2 y 3 días para el tratamiento sh3. Luego se adicionó para estos 3 tratamientos la misma cantidad de agua $(240 \mathrm{ml})$ cada día durante 2 meses. El testigo (T) se regó cada 4 días, adicionando $2.000 \mathrm{ml}$ de agua. Estos riegos se realizaron considerando los valores evapotranspiración máxima (ETM) y los coeficientes hídricos estimados en los experimentos sobre las necesidades hídricas de la arracacha (Blas, 2000). Se utilizaron 5 plantas por cada tratamiento, por un período de dos meses.

Segundo ensayo: se probó la respuesta a la inducción floral del peso y niveles de deshidratación de los colinos.

\section{Peso y niveles de deshidratación de los colinos}

Se utilizaron las entradas AYAC-1 y AYAC-2 (Tabla 1). Los "colinos" fueron repartidos en tres clases, según el peso (<35 g, entre 35-50 g y >50 g). Luego, los colinos de cada clase (en peso) fueron deshidratados en tres niveles de pérdida de su peso $(40-50 \%, 50-60 \%$ y $>60 \%)$ a temperatura ambiente (laboratorio, $20{ }^{\circ} \mathrm{C}$ ). Luego, 5 colinos por tratamiento fueron plantados en una cámara (a una temperatura constante de $20^{\circ} \mathrm{C}$ y a un fotoperíodo de $12 \mathrm{~h}$ ) y en un invernadero con una temperatura de $25-35^{\circ} \mathrm{C}$ y un fotoperíodo de $13-15 \mathrm{~h}$. Las siem- 
bras se realizaron escalonadas, durante 26 días, en función del nivel de deshidratación deseado.

\section{Estimación de la viabilidad polínica}

La viabilidad polínica fue estimada en las tres principales formas hortícolas: blanca (RBS-15), amarillo (RBS-16) y púrpura (RBS-17). Estas plantas fueron inducidas a la floración en la cámara acondicionada. Se tomaron 10 flores por genotipo; cada flor proviene de plantas diferentes (a excepción de RBS-17, donde las flores fueron tomadas de una sola planta).

Durante las horas matinales, las flores frescas abiertas, con los estambres dehiscentes fueron muestreados. Los estambres fueron sacudidos sobre una lámina porta objeto. Se puso una gota de aceto carmín a $45 \%$ y se cubrió con una lámina cubre objetos. La coloración fue suficiente después de aproximadamente 15 minutos. El recuento fue realizado bajo un microscopio óptico, 200 granos de polen por flor. Los granos de polen fértiles aparecen de color rojo con una forma característico de la especie y los no viables aparecen sin coloración y deformado.

El carmín acético es un colorante de los componentes del citoplasma. La metodología se basa sobre la hipótesis que solamente las células con una membrana intacta y funcional pueden ser coloreadas. Sin embargo, algunos granos de polen con un citoplasma degenerado o muerto pueden ser coloreados (Janssen \& Hermsen, 1976, citado por Knudsen, 1999). Así que esta técnica puede sobreestimar la fertilidad (Jahier et al., 1992). Pero, la metodología es simple y ha presentado resultados fiables en la estimación de la viabilidad de polen.

\section{RESULTADOS Y DISCUSIONES}

\section{INDUCCIÓN FLORAL EN LA ARRACACHA}

En el primer ensayo, las entradas RBS-15 y RBS-16 provenientes de los "colinos" deshidratados a $60 \%$ presentaron un porcentaje de inducción floral semejante, en promedio $61 \%$, tanto en las condiciones de la cámara acondicionada como en el invernadero (Tabla 2). Estos resultados confirmarían las observaciones de Bajaña (1994), Hermann (1997) y Knudsen (1999), quienes afirman que el estrés hídrico sería probablemente uno de los factores más importante de la inducción floral en la arracacha. En consecuencia, parecería que la deshidratación induciría la floración en la arracacha. Estas observaciones sugieren que el ancestro silvestre potencial de la arracacha florece después de un período extendido de sequía (Hermann, 1997, Blas, 2005). Por el contrario, otras especies de la familia Apiaceae del viejo mundo, tal como el apio, zanahoria, perejil (Petroselinum crispum (Mill.) A.W.Hill) presentan una floración inducida por la vernalización (Mathon \& Stroun, 1962; Rubatzky \& Yamaguchi, 1997).

Sin embargo, en la entrada RBS-17, una sola planta floreó en la cámara acondicionada. Esto indicaría que la inducción floral en la arracacha dependería del genotipo; es decir, ciertos genotipos serían más aptos para la floración que otras en las condiciones de estrés hídrico. Esta hipótesis tiene soporte en los trabajos de Hermann (1997), de Bajaña (1994), de Knudsen (1999). También se han observado floraciones con esta tendencia en diferentes bancos de germoplasma en Perú, tales como Centro Internacional de la Papa, Lima; Instituto

Tabla 2

Tratamientos y porcentaje de inducción floral en la arracacha

\begin{tabular}{|l|l|c|c|c|}
\hline Entrada & Condiciones & $\begin{array}{c}\text { Número “colinos” } \\
\text { sembrados }\end{array}$ & $\begin{array}{c}\text { Número de plantas } \\
\text { en floración }\end{array}$ & $\begin{array}{c}\text { Inducción floral } \\
(\%)\end{array}$ \\
\hline RBS15 & Cámara & 80 & 53 & 66,3 \\
RBS16 & 40 & 23 & 57,5 \\
RBS17 & 33 & 1 & 3,0 \\
RBS15 & Invernadero & 40 & 25 & 62,5 \\
RBS16 & 20 & 12 & 60,0 \\
\hline
\end{tabular}


Nacional de Investigación Agraria, Cajamarca (observación personal).

Los tratamientos de los niveles de estrés hídrico al sustrato que fueron aplicados para la entrada RBS-15, en las condiciones controladas de temperatura diurna $\left(22^{\circ} \mathrm{C}\right)$, nocturna $\left(10^{\circ} \mathrm{C}\right)$ y un fotoperíodo de 12 horas, no presentó ninguna inducción floral. Sin embargo, no hay que olvidar que otros colinos del mismo clon presentaron inducción floral después de una deshidratación de los colinos a $60 \%$ (Tabla 2).

La explicación podría ser que ciertos "colinos" tienen madurez apropiada, acumulando suficientemente hidratos de carbono. Una intensidad de la luz más elevada favorece también la floración, ya que la luz permite el aprovisionamiento en hidratos de carbono (Koornneef, 1998). En consecuencia suponemos que los "colinos" que no proporcionan los ejes florales no son fisiológicamente maduros y necesitan aportes en elementos nutritivos.

\section{PESO Y DESHIDRATACIÓN DE LOS COLINOS}

En el segundo ensayo, en la prueba de los diferentes niveles de deshidratación de los"colinos" con los diferentes pesos de los "colinos" muestreados, ninguna de estas entradas, AYAC-1 y AYAC2 , presentaron floración.

Las condiciones que preceden (responsables) a la inducción floral aún no son bien conocidas. Las afirmaciones que indican que la arracacha tiene tendencia a iniciar su floración en días cortos $(12 \mathrm{~h})$ con temperaturas bajas $\left(10^{\circ} \mathrm{C}\right)$ y bajo un estrés hídrico, no se confirman por nuestros ensayos. Comportamientos diferentes pueden también ser observados según los genotipos. Es necesario analizar otros factores ambientales que podrían favorecer la floración.

En el género Arabidopsis, la sensibilidad a los factores ambientales depende fuertemente del genotipo. Se piensa que estos factores ambientales pueden modular ciertos componentes endógenos, lo que afecta y controla la floración (Koornneef et al., 1998). Se han identificado alrededor de 80 genes en Arabidopsis que afectan el período de floración, a través de la variabilidad genética del período de floración natural presente entre les ecotipos y/o la utilización de la variación genética inducido por los tratamientos mutagénicos (Koornneef et al., 1998, Simpson et al., 1999). Hay diferentes vías de control del período de la floración en Arabidopsis. Dos de estas vías son las señales ambientales: la vía fotoperiódica ("photoperiod promotion pathways"), o respuesta normal a la transmisión día-noche, y la vía de vernalización ("vernalization promotion pathways"), o respuesta a bajas temperaturas. Por otro lado, hay otro grupo de genes que provocan la floración independientemente de las señales ambientales. Estos genes son conocidos como vías autónomas ("autonomus promotion pathway"); responden probablemente a las señales endógenas tal como un reloj interno de desarrollo. El ácido giberélico presenta una vía de promoción diferente de otros (Simpson et al., 1999). Además, la regulación de la expresión de genes por la metilación directa de ADN podría jugar un rol importante en estos procesos.

\section{VIABILIDAD POLÍNICA}

La viabilidad polínica (granos coloreados) en las tres formas hortícolas es semejante y en promedio es de 95\% (Figura 2). Sin embargo, Knudsen (1999) encontró diferencias de viabilidad de los granos de polen en función de los genotipos (40\% a 62\%). Entonces, los resultados dependerían de los genotipos y de las condiciones medioambientales. Las condiciones medioambientales óptimas no serían las mismas para la inducción floral y la antesis. Nuestras condiciones no serían ideales para la inducción floral pero, por el contrario, son buenos para la antesis ( $95 \%$ polen viable).

En nuestras condiciones no se observó ninguna formación de semilla en las plantas en floración, a pesar que la viabilidad del polen fue de alrededor de 95\%. La ausencia de fecundación puede ser explicada por el fenómeno de protoginia (es decir, la receptividad del estigma antes de la apertura de las anteras). Según Hermann (1997) la duración de la receptividad del estigma es del orden de 3 a 4 días. Este fenómeno favorece la alogamia en la arracacha. El período de floración fue aproximadamente de 5 meses en nuestras condiciones y diferentes umbelas presentan flores en diferentes estados de desarrollo. En consecuencia, sobre una misma planta se pueden observar flores en antesis y flores con estigma receptivo. La autofecundación, entonces, no es imposible. En invernadero, la ausencia de viento y de insectos frenan las condiciones de fecundación. Además las temperaturas elevadas (sobre los $35^{\circ} \mathrm{C}$ ) pueden tener una influencia negativa sobre la fecundación: las anteras se desecarían e impediría la liberación del polen (Hermann, 1997, Knudsen, 1999). 


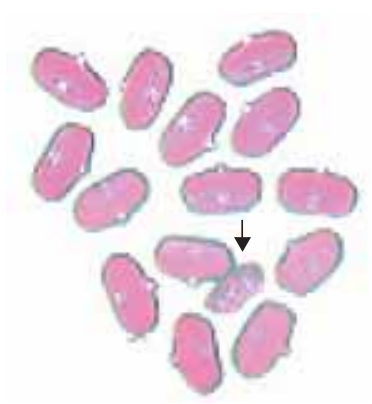

A. Granos de polen viables, y grano no viable (indicado con la flecha).

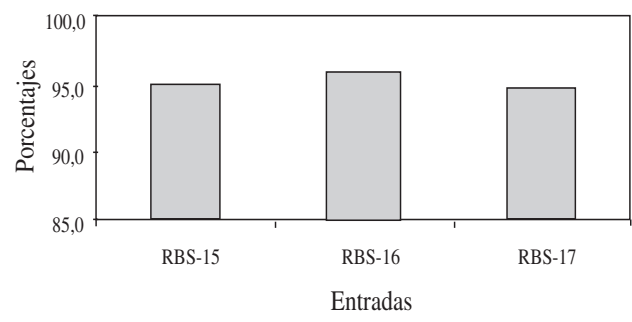

B. Porcentaje de la viabilidad polínica en la arracacha.

Figura 2. Viabilidad de los granos de polen de arracacha estimada con acetocarmin.

En conclusión, los resultados concernientes al estrés hídrico y la deshidratación de los "colinos" no permitieron poner en evidencia una tendencia clara sobre la inducción floral de la arracacha. La floración es variable según los genotipos. Entonces, para comprender los procesos de la floración en la arracacha, al nivel anatómico, fisiológico y molecular es ne-

\section{LITERATURA CITADA}

BAJAÑA, D. F. 1994. Efectos de factores ambientales sobre la floración de zanahoria blanca (Arracacia xanthorrhiza Bancroft). Tesis, Licenciado Ciencias Biológicas, Pontificia Universidad Católica del Ecuador, Facultad de Ciencias Exactas y Naturales, Departamento de Ciencias Biológicas, Quito, Ecuador, 116 p.

BLAS, R. 2000. Diversité génétique et éléments de physiologie chez l'arracacha (Arracacia xanthorrhiza Bancroft). Mémoire de fin d'etudes du Diplome d'Etudes Approfondies, Faculté Universitaire des Sciences Agronomiques de Gembloux, Belgique, $67 \mathrm{p}$.

BLAS R. 2005. Diversity of Arracacia species in Peru. Ph.D. thesis. Gembloux Agricultural University, Belgium, $154 \mathrm{p}$.

BRAKO, L. \& J. ZARUCCHI. 1993. Catálogo de las angiospermas y gimnospermas del Perú. Missouri Botanical Garden, $1.286 \mathrm{p}$.

CÁRDENAS, M. 1969. Manual de plantas económicas de Bolivia. Segunda edición. Editorial los Amigos del Libro. La Paz, Bolivia, $51 \mathrm{p}$.

HERMANN, M. 1997. Arracacha (Arracacia xanthorrhiza Bancroft). In : Andean roots and tubers: Ahipa, arracacha, maca and yacon. Promoting the conservation and use of underutilized and neglected crops. Hermann, M. and J. Heller (eds). 21. Institute of Plant Genetics and Crop Plant Research, Gatersleben/ International Plant Genetic Resources Institute, Rome, Italy, p. 75-172.

HODGE, W.H. 1954. The edible arracacha- a little- known root crop of the Andes. Economic Botany 8 (3): 195-221.

JAHIER, J., A. M. CHEVRE, F. EBER, R. DELOURME \&

A. M. TANGUY. 1992. Techniques de cytogénétique vé- cesario estudiar en aquellos genotipos de fácil inducción floral. Estudios de cambios morfológicos al nivel de meristemas, análisis de las concentraciones de los reguladores de crecimiento como el del ácido giberélico, análisis molecular utilizando como sondas los genes identificados en Arabidopsis u otras especies que controlan la inducción floral. gétale. J. Jahier (ed.) Institute National de la Recherche Agronomique (INRA), Paris, France, $184 \mathrm{p}$.

KOORNNEEF, M., C. ALONSO-BLANCO, A. J. M. PEETERS \& W. SOPPE. 1998. Genetic control of flowering time in Arabidopsis. Annu. Rev. Plant Physiol, 49: 345-370.

KNUDSEN, S. 1999. Flower inducción in the Andean root crop arracacha (Arracacia xanthorrhiza Bancroft). A description and evaluation of the morphological changes following dehydratation. Thesis M.Sc. in Bothany, The Royal Veterinary and Agricultural University Copenhagen, Denmark, $71 \mathrm{p}$.

LEÓN. J. 1964. Plantas alimenticias andinas. Boletín Técnico $\mathrm{N}^{\circ}$ 6. Instituto Interamericano de Ciencias Agrícolas de la Zona Andina. Lima, Perú, 112 p.

MATHIAS, M. \& L. CONSTANCE. 1962. Arracacia Bancroft. In: Mathias, M. E. and Constance L. (eds.) Flora of Perú. Field Mus. Nat. Hist. Bot. 13 (1) port V-A: 13-19.

MATHON C-C. \& M. STROUN. 1962. Température et floración (la vernalisation). Presses Universitaires de France, Paris, $125 \mathrm{p}$.

RUBATZKY, V. E. \& M. YAMAGUCHI. 1997. World vegetables. Principles, production, and nutritive values. 2 éd. Chapman and Hall New York: International Thomson Publishing, London, $843 \mathrm{p}$.

SIMPSON, G. G., A. R. GENDALL \& C. DEAN. 1999. When to Switch to flowering. Annu. Rev. Cell. Dev. Biol. 99: 519-550.

ZANIN, A. \& V. CASALI. 1984. Origem, distribução geográfica e botanica da mandioquinha-salsa. Informe agropecuario, Belo Horizonte, Brasil 10 (120): 9-11. 